\title{
A HAZARD OF SCAVENGER PORT DESIGN
}

\author{
RICHAKD M.M. FlowerdeW
}

\begin{abstract}
This case report describes an inadvertent misconnection of the breathing and scavenging hoses on the anaesthesia machine which resulted in complete expiratory obstruction. The features which facilitate such a misconnection are deseribed and modifications to reduce the likelihood of this event recurring are suggested.
\end{abstract}

KEY WORDS: SCAVENGING, anaesthetic gases; EQUIPMENT, failure.

A RECENT EDITORIAL by Miller and Cullen' concerning the risk/benefit ratio of scavenging anaesthetic gases and vapours closes with a plea for "more vigorous standards in the design of equipment and increased awareness of potential problems." This report describes a problem of scavenging which should be prevented by design features, of which three are suggested. The incident reported also demonstrated a factor to be considered when determining the position of the fresh gas inflow into the circle system.

A patient about to undergo an orthopaedic procedure was prepared for anaesthesia. The patient circuit (circle system) of the anaesthetic machine, which had been in use all day without difficulty, was checked for leaks as described in the criteria developed by N.I.O.S.H. ${ }^{2}$ and appeared satisfactory. Anaesthesia was induced with thiopentone. Respiration was then assisted with oxygen (five 1.p.m.); ventilation was judged to be adequate despite a leak around the mask. Succinylcholine was given, followed by another brief period of ventilation by mask. The trachea was then intubated without difficulty, using a $7 \mathrm{~mm}$ cuffed tracheal tube. The anaesthetic equipment in use included an Ohio $^{*}$ carbon dioxide absorber system with an Ohio ${ }^{\oplus}$ scavenging valve (Figure 1).

After the first few compressions of the reservoir bag, the lungs became increasingly difficult to ventilate. Good breath sounds were heard bilaterally, but expiration became progressively shorter. The airway pressure was rising and the chest was becoming hyperinflated. Disconnecting the circuit at the tracheal tube produced a prolonged expiration. The same sequence recurred on reconnecting the anaesthetic circuit. The tracheal tube was changed without benefit. The

Richard M.M. Flowerdew, M.B., B.S., F.F.A.R.C.S., Department of Anesthesiology, Maine Medical Center, Portland, Maine 04102, U.S.A.

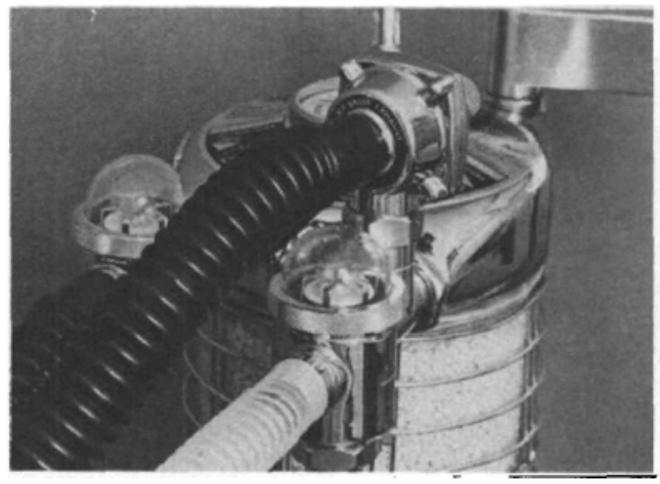

Figure 1 Ohio ${ }^{\text {(1) }}$ valve ports on carbon dioxide absorber. Inappropriate breathing and scavenger hose connections. White hose is for scavenging.

problem appeared to be related to the machine, not to the patient. It was then observed that the hoses on the machine were connected improperly (Figure 1). The expiratory limb of the black breathing circuit was connected to the exhaust port of the scavenging valve, and the white scavenging hose connected to the expiratory valve port. Correct placement of the hoses permitted proper ventilation and the anaesthetic proceeded without further incident. The patient suffered no apparent ill-effects.

\section{Discussion}

Several national bodies have recommended that anaesthetic vapours and gases should not exceed certain specified limits in hospital atmospheres. ${ }^{2.3}$ This can be achieved by adopting several different approaches including the collection of exhaust gases into a scavenging system. This technique calls for additional equipment. Unfortunately, the introduction and development of new devices increases the potential for equipment-related accidents.

Canad. Anaesth. Soc. J., vol. 28, no. 5, September 1981 
Accidents with medical gas cylinders resulted in the introduction of the pin index code to prevent incorrect connections. No code exists for scavenging hoses to distinguish them from the breathing hoses, despite the widespread use of scavenging systems for several years. If therc were such a code, this particular event would have been less likely. Currently, the scavenger outlet port is the same in size and appearance as the breathing circuit ports and is in close proximity to them (Figure 1,2). This invites inadvertent hose cross-connections. A similar event was reported by Tavakoli and Habeeb 4 in 1978, demonstrating that this accident has happened before and presumably will happen again, unless some feature is introduced to prevent such misconnections. In our particular case, the different colour of the hoses helped discover the fault (Figure 1).

This incident also demonstrated another factor in deciding the position for the inlet of the fresh gas flow in relation to the unidirectional valves on the circle system. If the fresh gas delivery hose is on the absorber side of the inspiratory valve (Figure 3) and the exhaust limb occluded (in this case by inappropriate connection to the scavenger valve), there is both reverse flow into he reservoir bag as well as flow into the inspiratory limb. Thus, a low pressure leak test which requires both closing the scavenger valve and occluding the patient end of the circuit, will be normal and the reservoir bag will also "feel" as expected. The inspiratory valve will move as expected, but the expiratory valve will not. It is important to note that the low pressure test only measures leak and not flow and this underlines the importance of checking flow as well as pressure. If the circuit with this configuration is

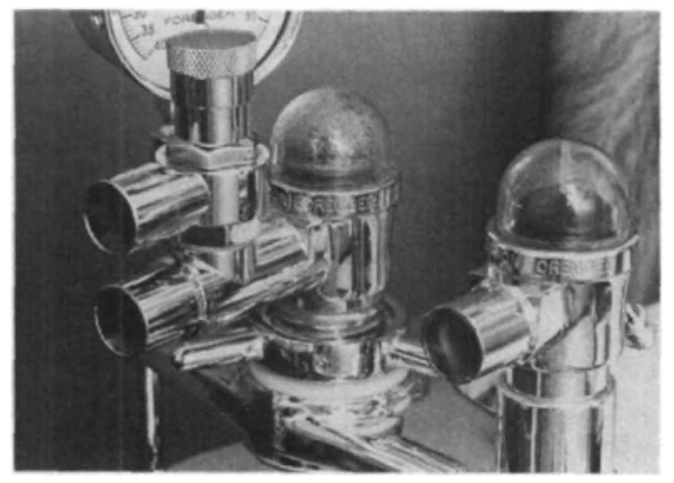

Figure 2 Foregge valve ports on carbon dioxide absorber. Similarlity in size and proximity invite misconnection as in Figure 1.

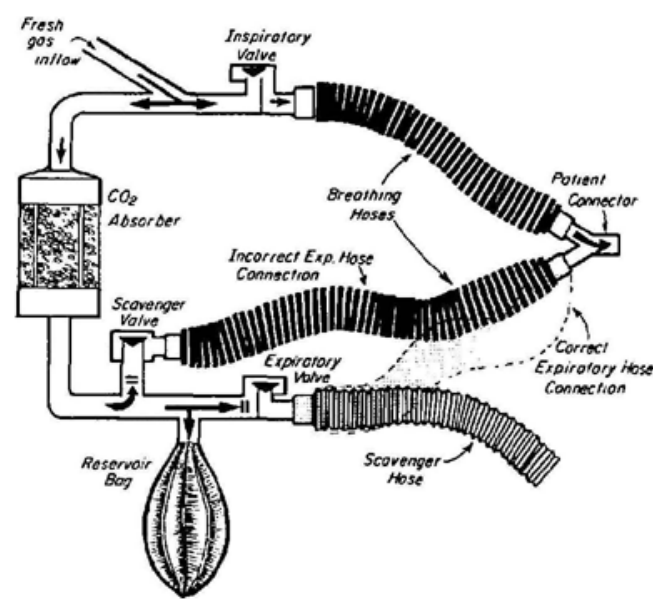

Figure 3 Circle system with inflow on absorber side of unidirectional valves. Note retrograde flow into the reservoir bag.

put into use without recognizing the fault, there will be a rise in airway pressure due to obstruction of the expiratory limb as was observed here and also by Tavakoli and Habeeb. ${ }^{4}$

If the fresh gas inflow is placed on the patient side of the unidirectional valves (Figure 4), then there is no reverse flow into the reservoir bag. Thus, when a low pressure leak test is undertaken, the bag will not fill. This should make it apparent that there is a problem. A pressure relief mechanism such as a Norry pressure limiting valve, on the fresh gas delivery hose would reduce the potential for pulmonary barotrauma in either configuration.

It is clear that a meticulous check of equipment would have located this fault. The similarity between the hose ports, however, and the ability for the fresh gases to fill the bag in certain configurations makes it likely that the event will recur. This hazard could be reduced by adequate design standards for scavenger systems.

There are at least three features that would reduce the likelihood of this misconnection. The first of these would be to fix the exhaust port of the scavenger valve so as to exit horizontally, but in the opposite direction to the breathing valve ports. The immediate proximity of all three ports was an important contributing factor in this incident.

Second, the diameter of the scavenger hose could be made different from the diameters of the breathing hoses or altered to the shape of a star, square, or triangle. In practice, it is easier to maintain the round shape of the port.

Thirdly, the introduction of a standard colour 


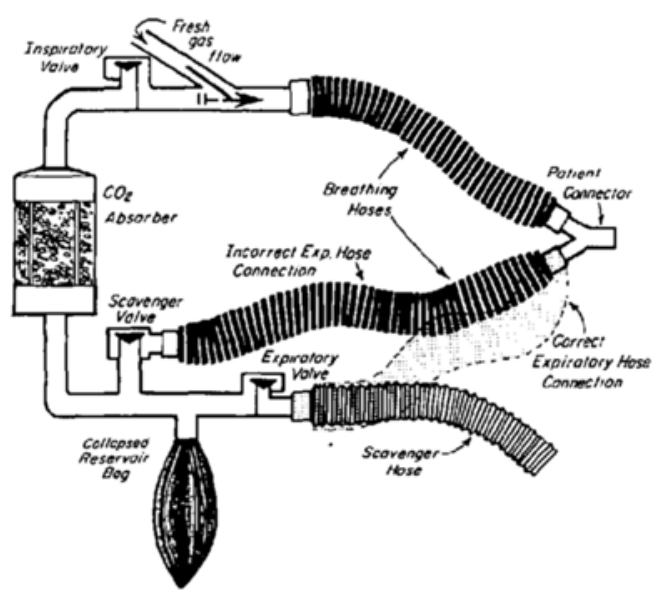

FIGURE 4 Circle system with inflow on patient side of unidirectional valves. Note no retrograde flow into the reservoir bag.

or markings for scavenging lines would help distinguish between the respective systems. In this particular incident, it was the different colour of the hoses that drew attention to the wrong connection, and would support those who have already made this suggestion. ${ }^{s}$

The final resolution of this dangerous problem lies with anaesthetists, manufacturers and the Standards Organizations as a uniform safe system is desirable. These latter organizations have undertaken extensive work on scavenging and are in the final stages of producing a Standard ${ }^{6,7}$ covering all aspects including discrimination between scavenging and breathing hoses. It is proposed to achieve this by making the scaveng- ing connector $19 \mathrm{~mm}$ or $30 \mathrm{~mm}$ diameter. However, there is still no substitute for a meticulous check of anaesthetic equipment before use.

The author is grateful to C.W. White, M.D. and D.A. Pelton, F.R.C.P.(C) for reviewing this manuscript, to Ethel Cleaves for typing the manuscript and the Audio-visual Department at Maine Medical Center for the photographs and diagrams.

\section{REFERENCES}

1. Miller, M.G. Cullen, B.F. The Cost of Scavenging - Is It Worth It? Anesthesia and Analgesia 58: 265-66 (1979)

2. Criteria for a Recommended Standard: Occupational exposure to waste anaesthetic gases and vapours. Washington, D.C. U.S. Govt. Printing Office DHEW Publ no. NIOSH 77-140 (1977).

3. Pollution of Operating Departments, etc. by Anaesthetic Gases. Department of Health and Social Security. Health Services Division, 2B. Hannibal House, Elephant and Castle, London SEI 6TE England. HC (76) 38 (July, 1976).

4. Tavakoli, M. \& Habeeb, A. Two Hazards of Gas Scavenging. Anesthesia and Analgesia 57: 286-87 (1978).

5. WYANT, G.M. Mechanical Misadventures in Anaesthesia. University of Toronto Press (1978).

6. LECKY, J.H. Proposed Draft Standard (13th Draft) Z79.11 Anaesthesia Gas Pollution Control. Sub. committee on Anesthesia Gas Scavenging Devices and Disposal Systems. American National Standards Committee Z79.

7. Canadian Standards Association, Draft Standard Z168.8: Anaesthetic Gas Scavenging Systems (Second Draft September 1980, Revised February 1981).

\section{RÉSUMÉ}

L'auteur décrit une erreur de raccordement entre les conduits du circuit respiratoire et du dispositif anti-pollution d'un appareil d'anesthésie qui fut la cause d'une obstruction expiratoire complète. Les caractéristiques qui ont facilité cette erreur sont décrites et certaines modifications qui peuvent en rẻduire l'éventualité sont suggẻrées. 